\title{
O USO PEDAGÓGICO DA TÉCNICA CINEMAGRAPHS PARA A CONSTRUÇÃO DE FANFICTIONS
}

\author{
Patrícia da Silva Campelo Costa - PPGIE/ UFRGS - patricia.campelo@yahoo.com \\ Anelise Jantsch - PPGIE/ UFRGS - anelise.jantsch@ gmail.com \\ Patrícia Fantinel - PPGIE/ UFRGS - patifantinel@gmail.com \\ Maria Cristina Villanova Biazus - PPGIE/UFRGS - cbiazus@ufrgs.br \\ Eliseo Berni Reategui - PPGIE/UFRGS - eliseoreategui@gmail.com \\ José Valdeni Lima - PPGIE/UFRGS - valdeni@inf.ufrgs.br
}

\begin{abstract}
Resumo: Este artigo apresenta uma discussão acerca das possibilidades de uso pedagógico de uma nova técnica de edição de imagens (cinemagraphs) na construção de narrativas visuais em contexto escolar. Tal técnica pode ser uma aliada no processo de elaboração de histórias conhecidas como fanfictions, nas quais novas tramas são criadas a partir de elementos culturais já reconhecidos na mídia. Visto que a geração digital de estudantes tem a oportunidade de lidar com a imagem em suas mais diversas formas, procura-se neste estudo relacionar a técnica cinemagraphs com o processo composicional de fanfictions, de modo a discutir como diferentes linguagens podem ser trabalhadas em sala de aula. Espera-se com isso ampliar as possibilidades de aplicação pedagógica em áreas multidisciplinares, de modo que a tecnologia propicie a inclusão de diversas linguagens no processo educacional.
\end{abstract}

Palavras-chave: cinemagraphs, fanfiction, imagem.

\section{PEDAGOGICAL USE OF THE CINEMAGRAF TECHNIQUE IN THE DEVELOPMENT OF FANFICTIONS}

\begin{abstract}
This article presents a discussion about the possibilities of pedagogical use of a new technique for edition of images (cinemagraphs) in the development of visual narratives. This technique can aid the construction of fanfiction stories - narratives which are created based on cultural elements recognized on the media. Since the generation of digital students has the opportunity to deal with image in various ways, this study seeks to intertwine the cinemagraph technique with the compositional process of fanfictions, in order to discuss how different systems of languages can be covered in school. Therefore it is expected that this application may extend the possibilities of teaching in multidisciplinary areas, so that technology triggers the inclusion of several systems of languages in the educational process.
\end{abstract}

Keywords: cinemagraphs, fanfiction, image. 


\section{Introdução}

A web 2.0 caracteriza-se pela crescente propagação de produções elaboradas por diversos indivíduos, coletivamente ou não, que são postadas e apreciadas por comunidades online. Um exemplo desse tipo de produção se dá através da criação de fanfictions, narrativas que incluem elementos da mídia, derivados de seriados, filmes, etc. São justamente ficções criadas por fãs (Black, 2009), visto que novos enredos são concebidos a partir de personagens e histórias da mídia já pré-existentes.

Dessa maneira, conforme afirma Souza (2006, p.4), "alimentar o olhar deveria fazer parte da escola de maneira incisiva, pois as crianças chegam ali com o olhar carregado de referências pessoais e culturais". Assim, essa experiência extra-escolar dos alunos pode ser aproveitada em aula a partir de atividades focadas nas suas preferências enquanto fãs de ícones das mídias. Procuramos, então, propor a elaboração de fanfictions em formato visual a partir do uso de uma técnica há pouco concebida, conhecida como cinemagraphs. De acordo com tal procedimento, uma imagem digital é criada, de modo que haja uma repetição no movimento, de forma semelhante a uma animação. No entanto, em vez de toda a imagem estar em movimento, apenas uma parte dela se altera. A partir dessa criação de Beck e Burg (2010), o aluno pode focalizar elementos específicos da narrativa a ser criada, de modo a compor uma história visual envolvendo diversas linguagens.

Dentro dessa perspectiva, este estudo objetiva discutir como a inserção de diversas linguagens, a partir da manipulação da técnica cinemagraphs na elaboração de fanfictions, pode ser útil no processo educacional. $\mathrm{O}$ intuito é ampliar o debate a respeito de novas metodologias de aplicação das tecnologias na educação, de modo a ir ao encontro do perfil da geração digital.

\section{A imagem e o cotidiano}

Nossa sociedade utiliza de forma intensa grande quantidade de imagens, que estão presentes em diversos lugares, seja na publicidade, nos bens de consumo, em casa, na escola, etc. A observação de uma imagem frequentemente mobiliza elementos como sentidos, percepções e pensamentos que não estão explicitamente contidos na ilustração.

Segundo Stephens (1998, p.11), há alguns anos a imagem vem substituindo a palavra como um veículo de "transporte mental". Assim, novas gerações tendem a estar ainda mais relacionadas ao poder da imagem, produzindo na web narrativas que mesclam as linguagens escrita e visual. Fonseca (2006, p.4) inclusive afirma que "não podemos trabalhar com a imagem como se ela fosse transparente e sim entendê-la como linguagem, produzida dentro de um contexto sócio-histórico e cultural'". De fato, as novas gerações que estão produzindo materiais online trabalham de maneira natural com diversas linguagens, visto que seu contexto cultural permite uma imbricação de linguagem nunca antes vista.

Conforme Sardelich (2006) o processo de leitura de imagens requer as seguintes competências por parte do leitor:

- iconográfica - reconhecer formas visuais que reproduzem ou não algo que existe na realidade;

- narrativa - estabelecer uma sequência narrativa entre elementos que aparecem na imagem e/ou elementos de informação complementar (título, data, local etc.); 
- estética - atribuir sentido estético à composição;

- enciclopédica - identificar personagens, situações, contextos e conotações;

- linguístico-comunicativa - atribuir um tema, um assunto que poderá contraporse ou coincidir com as informações complementares;

- modal - interpretar o espaço e tempo da imagem.

Como podemos observar, existe uma complexidade a ser explorada na exposição, manipulação e criação de imagens, sejam essas estáticas ou móveis. Segundo Nova (2003), imagens artificiais correspondem àquelas produzidas, como tais, pela ação humana, quer seja para tentar reproduzir ou documentar imagens naturais, ou para evocar sentimentos e emoções. Entre essas, incluem-se as pinturas, esculturas, os desenhos, as fotografias, o cinema, etc. Com a criação das imagens tecnologicamente reprodutíveis, inicialmente com a fotografia, o universo imagético vai rapidamente se ampliando. A vida torna-se uma verdadeira "tela viva" onde se percebe que há uma tênue linha entre o real e sua representação. É um processo de estetização do real, dos sujeitos e da vida, com o predomínio da imagem, do visual e do audiovisual. Segundo Santaella (2007, p.387-388):

[...] a duplicação imagética do mundo, que teve início com a fotografia no século XIX, atinge hoje proporções exacerbadas. Qualquer coisa, qualquer situação, todo o visível se tornou reprodutível. Além de reprodutível, portátil. Além de portátil, fluido. Além de fluido, transitável a qualquer canto do mundo.

As novas tecnologias imagéticas, em especial as de suporte digital, abrem um imenso potencial para a criação de novas formas de comunicação, que certamente superarão os limites tantos dos textos escritos quanto dos audiovisuais clássicos, tão caros à modernidade e à chamada "Era da Imagem". Esse potencial diz respeito, sobretudo, a três possibilidades: a mesclagem de diversas linguagens num único suporte, a ampliação das formas de interatividade e a viabilização de produções coletivas (Nova, 2003). É com base nesse potencial que acreditamos na capacidade do uso das tecnologias imagéticas como contribuição no processo educacional, como forma de integrar saberes entre professores e alunos, bem como de aproximar a escola da vida cotidiana altamente tecnológica que vivemos.

\section{Algumas possibilidades de uso pedagógico de imagens}

Park (2001) apresenta diferentes projetos pedagógicos utilizando a fotografia como possibilidade de registro e construção de conhecimentos do cotidiano. A autora aborda a educação do olhar, apontando que a utilização da imagem não pode ser de mera ilustração, mas de suporte para atividades pedagógicas. Já Souza e Lopes (2002) abordam um trabalho que utiliza a fotografia, desenvolvido tanto por alunos do ensino regular como por pessoas com necessidades especiais, no qual se buscou "facilitar a experiência de educadores e educandos com a produção e fruição de imagens visuais e mobilizar a produção de narrativas" (p.67). Nessa mesma pesquisa, também havia o objetivo de auxiliar na superação do gesto automatizado do ato fotográfico e construir narrativas que propiciassem "reverter a experiência do olhar, enfrentando de modo crítico a banalização da experiência visual no mundo contemporâneo" (p.79). 
Fonseca (2006, p.1) acredita que "lidar com imagens, lê-las com competência, perceber seus recursos e nuances faz parte do processo de apreensão, leitura e compreensão do mundo e de nossa própria existência". Assim, a inclusão de atividades na escola que lidem com o processo de leitura de imagens e composição de projetos a partir delas parece ser essencial para uma aprendizagem multidisciplinar.

Por sua vez, Borzato (2009) relata uma experiência com alunos adolescentes e aprendizes da EJA (Educação de Jovens e Adultos), os quais criaram fotonovelas editadas no software Gimp $^{l^{\prime}}$ a partir de fotografias captadas por eles próprios, durante projetos com seus colegas. Ainda em contexto escolar, Pinto (2010) incentiva a escrita na forma de produção de filmes, visto que os alunos escolhem ou escrevem uma história, criam roteiro, filmam, editam e, após esse processo exibem sua produção coletiva num festival da escola. Além disso, como possibilidade pedagógica de uso de imagens, é recorrente a utilização da técnica de animação Stop Motion ${ }^{2}$. Tal procedimento, muito reconhecido em animações do cinema, utiliza-se de uma sequência de fotografias diferentes de um mesmo objeto inanimado, a fim de simular seu movimento. Essas fotografias, chamadas de quadros, são tiradas de um mesmo ponto, com o objeto sofrendo uma leve mudança de localização. Assim, para produzir essa técnica são necessários apenas uma máquina digital, um computador com um programa de edição de vídeo e um roteiro.

Por fim, como alternativa pedagógica do uso de imagens temos a sugestão de Glenn Wiebe (Wiebe, 2011), especialista curricular da área de Estudos Sociais e Integração Tecnológica da ESSDACK (Educational Services and Staff Development Association of Central Kansas), o qual sugere a criação de uma história com cinco fotografias (Five Photo Story) em que a sequência de fotos deva contar uma narrativa visual. A única parte escrita é o título, e as fotos podem ser retiradas pelo aluno ou capturadas do ambiente online. $\mathrm{O}$ autor aponta diretrizes para estruturar a narrativa, uma vez que para ele uma boa história deve incorporar os seguintes tipos de imagem: cover shot para determinação do(s) personagem(ns) e localização; establishing shot para criação de situações com possibilidades do que venha acontecer; detail shot para envolver o(s) personagem(ns) na situação; filler shot para construção de resultados prováveis e closing shot para oferecer um final lógico e satisfatório.

Segundo Biazus (2009, p. 11), a profusão de mídias que fornecem novas formas digitais de interação deve ser ressignificada pelos educadores antes que essas sejam utilizadas no contexto escolar. A autora afirma que

[...] é necessária uma problematização entre o que está presente na mídia, e como esta tecnologia pode chegar ao laboratório da escola. Como utilizar esta tecnologia que nos permite estes acessos de maneira a não apresentar respostas prontas e ser desafiadora da busca de novas respostas que façam sentido para quem a utiliza.

Dessa maneira, é necessário que o uso da tecnologia na sala de aula esteja aliado a um planejamento pedagógico significativo. A partir da interação entre professores e alunos, projetos que incorporem a mídia digital, por exemplo enfatizando o uso de imagens, tornam-se processos de construção autoral em aula. Neste trabalho, o foco é a produção de fanfictions, tendo como base o uso da técnica cinemagraphs. Para tanto, discutimos como a leitura de diversas linguagens, tais como a escrita, a visual, dentre outras, pode ser essencial para a construção de narrativas. Conforme Souza (2006, p.45), "quando se lêem várias linguagens, estabelecem-se mediações que estimulam nossas 
potencialidades", visto que "o contato com discursos verbais ou não-verbais deixa aberto o canal dos sentidos, das emoções e da percepção". Assim, a incorporação de novas tecnologias, quando relacionadas a projetos de criação coletiva, pode se tornar uma aplicação pedagógica em que diversas linguagens são contempladas.

\section{Fanfiction}

O gênero textual fanfiction ganhou impulsão na Internet, tendo em vista a possibilidade de divulgação dessas narrativas na rede. Black (2009) define fanfiction como uma escrita em que as histórias são baseadas em personagens e sinopses já existentes na mídia e na cultura popular. De acordo com a autora, ao criar fanfictions, os fãs estendem as tramas e criam novas possibilidades narrativas entre os personagens de várias mídias. Jenkins (1992, 2009) inclusive focaliza o fenômeno conhecido como cultura participatória, a partir da qual os fãs produzem itens derivados de referenciais da mídia. Os criadores-fãs tendem, assim, a resgatar a riqueza dos recursos de textos escritos e/ou visuais, de modo a compor novas produções a partir de elementos da cultura popular, tais como filmes, seriados de TV, animes (animações japonesas), livros etc. Conforme Biazus (2000, p. 121) "buscar entender a produção artística enquanto resultado de um processo do ser humano remete para as questões que envolvem identidade e cultura". De fato, as produções de fanfictions de muitos sujeitos na web tornam-se formas artísticas validamente reconhecidas por uma comunidade online de apreciadores.

Além do gênero textual fanfiction, podemos observar a recorrente elaboração de histórias usando diferentes formatos, a partir da junção de imagens e/ou vídeos na criação de narrativas a serem divulgadas na Internet. Quando os indivíduos produzem fanvideos, eles se engajam no processo de construção narrativa por vontade própria. Segundo Jenkins (1992, p.233), tais vídeos comporiam "arte narrativa", através da qual são selecionadas imagens oriundas de narrativas pré-existentes. Para Ritchie (s.d), esses vídeos seriam materiais advindos da própria motivação do indivíduo, que tenta ativamente atrelar diferentes mídias (sejam essas visuais ou impressas). Tal entusiasmo na produção seria equivalente à criação de narrativas escritas (fanfictions). Ademais, o processo de criação se assemelha com o escrito, visto que em ambos os casos a narrativa é o elemento propulsor do vídeo ou da história escrita.

Para Ritchie (s.d), o uso de fanvideos em sala de aula indica uma tentativa de incorporação de habilidades composicionais dos alunos que muitas vezes já estão presentes em contexto extra-escolar. Além disso, ainda conforme o autor, o letramento em mídia visual é um componente essencial na vida dos alunos, visto que os recursos digitais enfatizam os papéis da imagem e do vídeo. Conforme Pinto (2010, p.1), ao produzir filmes na escola, "os alunos passam de receptores a produtores de material que pode ser utilizado na própria escola ou em eventos externos". Além disso, tal material pode ser postado em "sítios na Internet, que disponibilizam seus vídeos para o mundo inteiro" (p.1-2). Similarmente, a produção de fanfictions pelos jovens também é um processo fortemente calcado na questão da autoria. Desse modo, esses roteiristas-fãs se tornam autores genuinamente respeitados por comunidades online que admiram suas postagens. Observamos que os aprendizes podem, então, modificar seu papel de receptores culturais para se tornarem produtores ativos, ou seja, interatores. O termo interator vem do mundo do teatro, e autora Claudia Gianetti (2006) o adaptou para as mídias digitais, nas quais o sujeito além de expectador, ou seja, receptor é também agente modificador. 


\section{Produção de narrativas visuais através do cinemagraphs}

A fotógrafa Jamie Beck e o designer Kevin Burg criaram uma técnica de edição de imagem que se assemelha ao princípio dos gifs animados denominada cinemagraphs (Beck e Burg, 2010). Nessa técnica, apenas uma parte da imagem se desloca, visto que o efeito de movimento é focalizado em um ponto específico da figura ${ }^{3}$. Em uma das maneiras através das quais o cinemagraphs é feito, primeiramente fotografias são captadas e, posteriormente, o efeito de movimento do gráfico é aplicado. Conforme afirmam Beck e Burg (2010), esse seria um processo altamente colaborativo que requer um bom tempo de edição da imagem para que o efeito seja salientado na foto. Há uma fluidez na imagem, de modo que o observador não tem certeza se está observando uma foto, um gif ou um vídeo.

Assim, o aspecto principal do cinemagraphs é o foco em um ponto específico da imagem, de modo que a animação ocorra apenas na parte tratada pela edição. Na figura 1 são apresentadas algumas etapas para a construção de cinemagraphs ${ }^{4}$ utilizando o software Photoshop ${ }^{5}$. Conforme esse exemplo, observamos que na etapa (a) ocorre a importação de um vídeo para o Photoshop. Em seguida, um segmento desse vídeo (de 1 a 2 segundos) é selecionado e exportado como uma nova animação, a partir das opções File > Export> Render Video do Photoshop. Na fase seguinte (b), esse novo vídeo é transformado em quadros, de modo que uma cena específica da animação seja convertida em uma série de imagens estáticas. Para tanto, é necessário clicar em File> Import>Video Frame to Layers e selecionar o vídeo que anteriormente havia sido exportado. Assim, cada frame do vídeo será uma layer (camada) no processo de criação do cinemagraphs. Ainda nesta etapa uma foto de capa (camada principal) é selecionada. Logo a seguir, na etapa (c), a segunda camada é selecionada, e é criada uma máscara de camada (layer mask) sobre o ponto específico em que se quer movimento nesse layer. Esse procedimento da etapa (c) é repetido em todas as camadas, de maneira que ao final vejamos uma imagem estática com apenas uma área mascarada representando movimento. $\mathrm{O}$ trabalho com cinemagraphs possui um grande potencial para $\mathrm{o}$ desenvolvimento de atividades pedagógicas devido as suas características, uma vez que:

A linguagem visual é presentacional, isto é, desdobra-se ao olhar do leitor dentro de um espaço visível no qual não há um ponto de partida nem um ponto de chegada para o curso da leitura. Assim, ela difere dos textos verbais, que impõem uma forma para ser lidos: lemos da esquerda para a direita, sempre começando pela primeira palavra. Tal peculiaridade da imagem, no entanto, não é empecilho para um trabalho pedagógico; ao contrário, a complexidade da linguagem visual requer de nós verificar sua sintaxe para que possamos compreender melhor as mensagens visuais. (SECRETARIA MUNICIPAL DE EDUCAÇÃO/SP, 2006).

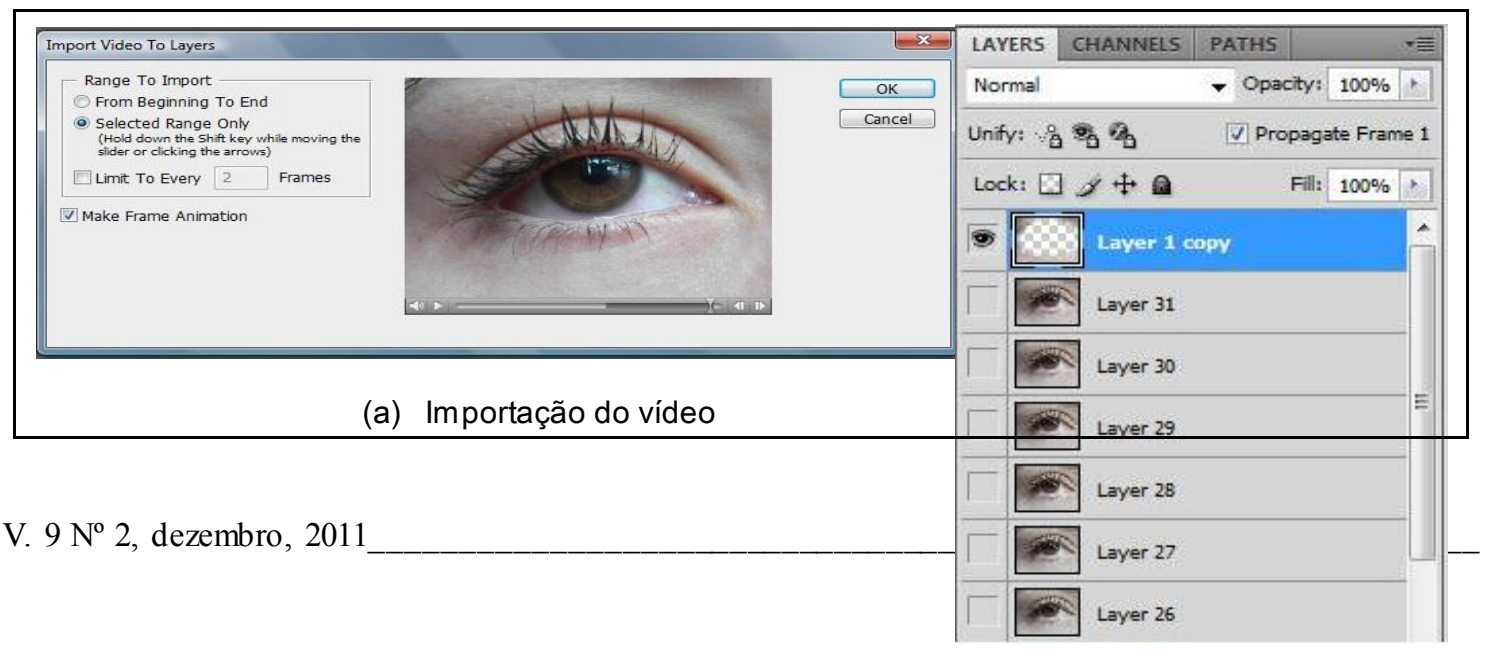




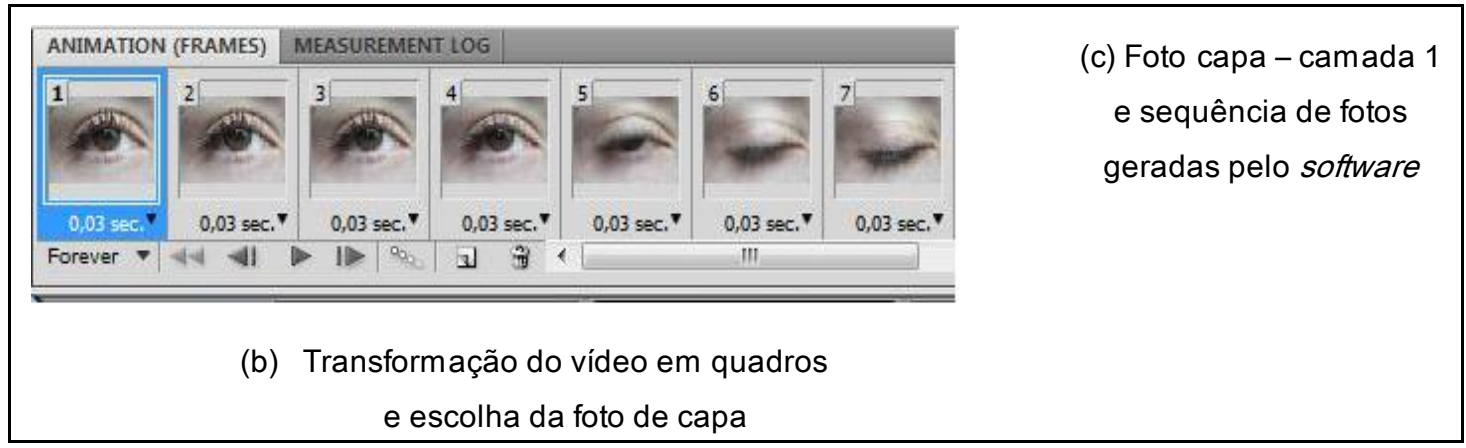

Figura 1 - Etapas para a construção de Cinemagraphs

Segundo Souza (2006, p.1), "a possibilidade de educar o olhar é uma ação que necessita ser intensa, profunda, pois só assim é possível avançar sobre os limites da escola e adentrar o cotidiano dos estudantes". Portanto, a partir de tal trabalho o aluno pode escolher imagens e/ou vídeos que se relacionem com elementos de seu cotidiano, de acordo com suas preferências, de modo que fanfictions visuais possam ser elaboradas. Tais produções podem, inclusive, ser semelhantes a fanvideos que incorporam partes de um vídeo derivado de um seriado específico, por exemplo. Um modelo é o vídeo Touradas ${ }^{6}$, no qual são observadas cenas do filme Crepúsculo e filmagens reais de uma tourada. Vemos, com esse exemplo, que trabalhos multidisciplinares podem ser conduzidos a partir dessa atividade.

Com a utilização específica do cinemagraphs, além de o aluno ter contato com uma técnica contemporânea de edição de imagem, há o fator de saliência do movimento. O cinemagraphs propicia ênfase em algum ou alguns elementos específicos da imagem. Assim, notamos que "a imagem está dentro de um espaço visual delimitado e exerce forte poder de sedução, porque convida nossos olhos a percorrê-la, envolvendo-nos [...] em um mundo fabricado por seu autor" (SECRETARIA MUNICIPAL DE EDUCAÇÃO/SP, 2006, p.29). Nesse caso, o novo autor da imagem será o aluno que propõe uma ênfase em pontos particulares da figura. A partir dessa especificação na imagem, há a possibilidade de um trabalho com questões pontuais de uma narrativa. Para Martins (1998, p.80):

você seleciona o que toca você. Por isso, faz um recorte da realidade, através de seu modo de ver o mundo [...]. Dessa forma, o resultado de qualquer produção artística que você faça terá, inevitavelmente, a sua marca [...] fruto do ser único que você é.

Logo, são contemplados aspectos de um letramento visual, a partir da construção que os alunos fazem da narrativa de imagens significativas para a criação de sua história. Em seguida, o letramento escrito também pode ser contemplado, tendo em vista que o processo de criação de narrativas escritas pode iniciar dessa compreensão de representações visuais.

No trabalho de Oliveira (2009), alunos do Ensino Fundamental tiveram que construir videoclips a partir de imagens da web. Para a autora, "a criação não se amparava na habilidade manual de fazer as imagens, mas na capacidade de conectar informações construindo um pensamento visual" (p. 69). De modo similar, durante a criação de narrativas visuais, com a utilização da técnica cinemagraphs, os alunos podem se apropriar de imagens da Internet e estabelecer novos significados a partir de 
novas contextualizações imagéticas. $\mathrm{Na}$ figura 2, a seguir, é apresentado um modelo com propostas de estratégias pedagógicas a partir do cinemagraphs.

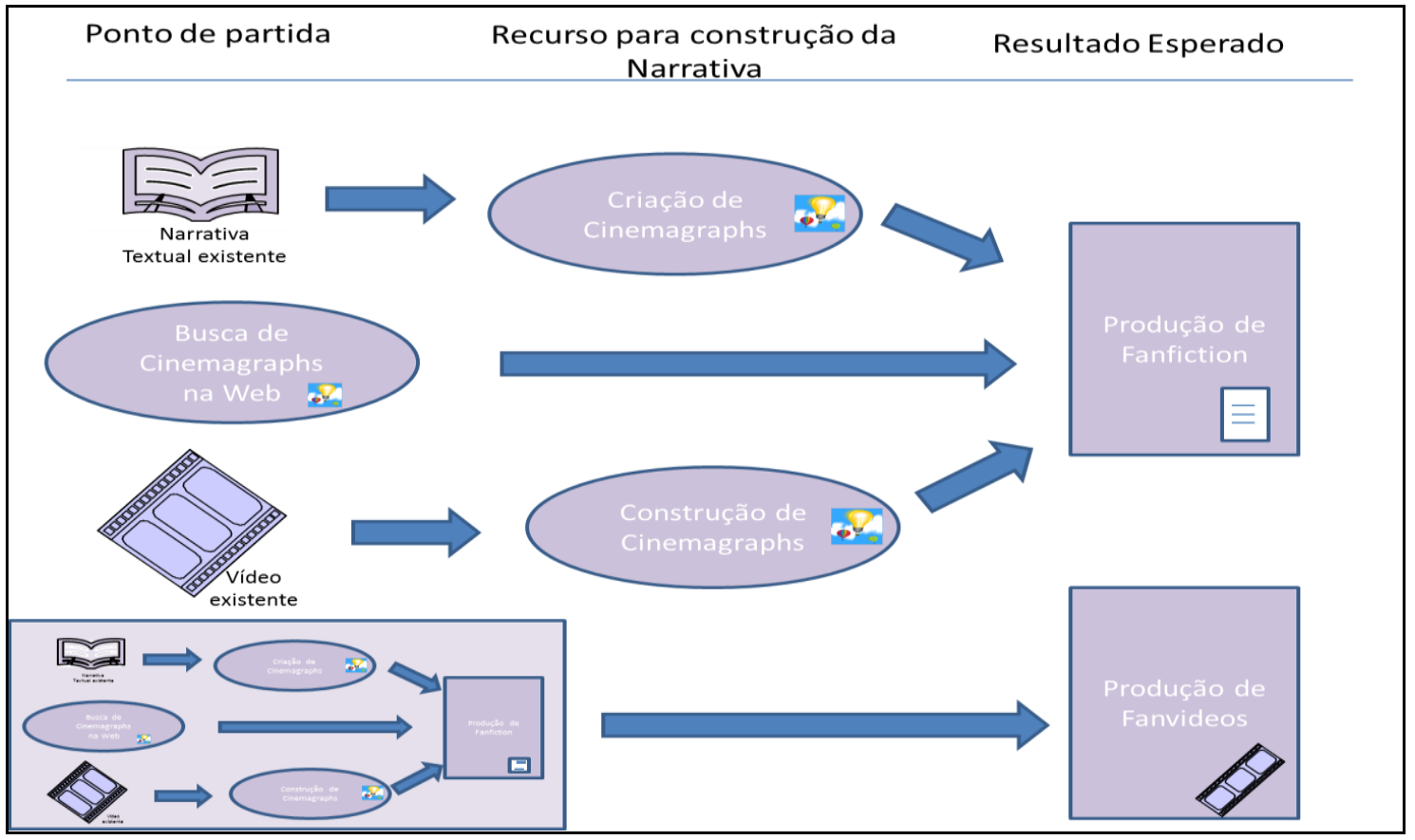

Figura 2 - Modelo de uso pedagógico do Cinemagraphs

Portanto como sugestões do uso pedagógico do cinemagraphs para a produção de fanfictions visuais temos: a) a partir de uma narrativa textual criar cinemagraphs que evidenciem detalhes para a produção de uma fanfiction; b) utilizar cinemagraphs disponibilizados na web e compor fanfictions; c) editar vídeos existentes para construção de cinemagraphs e, posteriormente, utilizá-los em fanfictions; d) a partir das fanfictions produzidas gerar fanvideos que podem resumir a narrativa (trailers) ou apresentá-la na íntegra em linguagem visual.

\section{Considerações Finais}

Em relação a implicações para estudos futuros relativos a esta pesquisa, estamos desenvolvendo a construção de fanfictions visuais através do uso de cinemagraphs com uma turma do Ensino Médio. O processo de construção das narrativas será observado, e para a análise da resposta do aluno a esse processo serão gerados dados a partir das seguintes fases: a) Observação direta, na qual as ações dos alunos enquanto desenvolvedores serão observadas (tal fase será gravada em vídeo e em um software de captura de tela); b) Auto-relato, em que os aprendizes farão um relato oral sobre suas experiências de manipulação da tecnologia e elaboração de fanfictions visuais; c) Sessão de visionamento, na qual os alunos observarão as gravações que foram realizadas e poderão detalhar as etapas do processo pelo qual passaram. Após a coleta desses dados e sua posterior análise, pretende-se verificar como esses procedimentos podem ser desenvolvidos de forma a mobilizar a inclusão de diferentes linguagens no contexto escolar.

Conforme Fonseca (2006, p.1), "as imagens constituem o nosso ser, elas, assim como as histórias, nos formam, informam e são também poderosas formas de comunicação". Então a partir da noção de imagem podemos trabalhar com narrativas 
significativas que incorporam a técnica cinemagraphs, a fim de propor trabalhos educativos que dêem conta de diversas linguagens. Além disso, é possível que haja ganhos multidisciplinares com este trabalho, visto que os aspectos a seguir podem ser enfatizados em sala de aula: linguagem visual; linguagem escrita; tomada de decisões; uso de multimídias em contexto escolar, a partir da utilização de softwares de edição de imagem; estruturação de narrativas; trabalho interdisciplinar; motivação para o trabalho em sala de aula; compreensão do tempo, movimento e velocidade; trabalho coletivo, dentre outros. Tais aspectos requerem um trabalho conjunto com professores de diversas áreas, a fim de que as possibilidades pedagógicas sejam usufruídas de modo interdisciplinar.

\footnotetext{
${ }^{1}$ Software de edição de imagem disponível no link: <http://www.gimp.org $>$.

2 Página da Internet com exemplos do uso de Stop Motion disponível no link: $<$ http://daa.caranguejo.com/atividade/4/45/1/1/oficina_virtual_de_stop_motion $>$.

${ }^{3}$ Páginas da Internet com vídeos que exemplificam a técnica de construção do cinemagraphs disponíveis nos seguintes links: $\quad<\mathrm{http}: / /$ www.youtube.com/watch? $\mathrm{v}=\mathrm{BTb}$ Ii0b-PHs \&feature=related $>$;

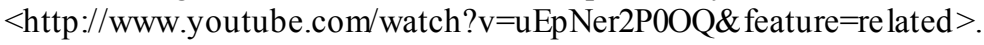

4 Página da Internet apresentando as etapas intermediárias disponível no seguinte link: $<$ http://blog.maris tane.com/2011/06/15/como-fazer-cinemagraphs-no-photoshop>.

5 Software de edição de imagem disponível no seguinte link: $<$ http://www.adobe.com/products/photoshop.html $>$.

6 Página da Internet com um exemplo de fanvideo, intitulado Touradas, disponível no seguinte link: $<\mathrm{http}: / /$ www.youtube.com/watch? $\mathrm{v}=\mathrm{xNFugBqjyc} 4 \&$ feature $=$ related $>$.
}

\section{Referências Bibliográficas}

BECK, J.; BURG, K. Cinemagraphs. From me to you. 2010. Disponível em: <http://fromme-toyou.tumblr.com> . Acesso em: 20 jun 2011.

BIAZUS, M. A imagem digital e o sujeito cognitivo-criativo. Informática na Educação: teoria e prática, v.3, n.1, p. 121-126, 2000.

BIAZUS, M. Em busca de processos para aprender Arte num mundo digital: uma Didática da Invenção. In: BIAZUS, M. (Org.) Projeto aprendi. Porto Alegre: Editora Promoarte, 2009.

BLACK, R. Online fan fiction, global identities, and imagination. Research in the teaching of English, v.43, n. 4, p. 397-425, maio 2009.

BORZATO, A. Animando histórias. In: BIAZUS, M. (Org.) Projeto aprendi. Porto Alegre: Editora Promoarte, 2009.

FONSECA, L. Leitura de imagens e a formação de leitores. Cadernos de Pesquisa, v.36, n.128, 2006.

GIANNETTI, C. Estética Digital: sintopia da arte, a ciência e a tecnologia. Belo Horizonte: C/Arte, 2006.

JENKINS, H. Textual Poachers: Television Fans and Participatory Culture. New York, NY, Routledge, 1992. 
JENKINS, H. Confronting the challenges of participatory culture: media education for the $21^{\text {st }}$ century. Massachusetts: MIT, 2009.

MARTINS, M. ; PICOSQUE, G.; GUERRA, M. Didática do ensino de arte: a língua do mundo - poetizar, fruir e conhecer arte. São Paulo: FTD, 1998.

NOVA, C. Imagem e Educação: Rastreando Possibilidades. In: ALVES, L.; NOVA, C. (Org.). Educação e Tecnologia: Trilhando Caminhos. Salvador: Editora da UNEB, 2003.

OLIVEIRA, A. Projetos pedagógicos em arte, educação e tecnologia. In: BIAZUS, M. (Org.) Projeto aprendi. Porto Alegre: Editora Promoarte, 2009.

PARK, M. Possibilidades de uso da fotografia na elaboração de projetos pedagógicos. Resgate - Revista Interdisciplinar de Cultura, n. 10, p. 39-58, 2001.

PINTO, E. A produção de vídeo na escola: aspectos sociais da informática na Educação. In: Anais do XXI Simpósio Brasileiro de Informática na Educação, 2010, João Pessoa.

RITCHIE, R. (s.d) Writing with Video: anime music videos and the composition process. Disponível em: <www.doki.ca/tmp/687\%20AMV.wps.rtf>. Acesso em 22 jun 2011.

SANTAELLA, L. Linguagens líquidas na era da mobilidade. São Paulo: Paulus, 2007.

SARDELICH, M. Leitura de Imagens, Cultura Visual e Prática Educativa. Cadernos de Pesquisa, v.36, n.128, p.451-472, 2006.

SECRETARIA MUNICIPAL DE EDUCAÇÃO/SP. Diretoria de Orientação Técnica. Referencial de expectativas para o desenvolvimento da competência leitora e escritora no ciclo II : caderno de orientação didática de Artes. São Paulo : SME / DOT, 2006.

SOUZA, M. Funções do estereótipo gráfico no desenvolvimento de competências de leitura. In: Anais do VI Encontro do Círculo de Estudos Linguísticos do Sul, 2006, Florianópolis.

SOUZA, S.; LOPES, A. Fotografar e narrar: a produção do conhecimento no contexto da escola. Cadernos de Pesquisa, n.116, p. 61-80, 2002.

STEPHENS, M. The rise of the image, the fall of the word. New York: Oxford, 1998.

WIEBE, G. Five Photo Story Telling. History Tech. 2011. Diponível em: $<$ http $/ /$ historytech.wordpress.com/2011/03/13/tip-of-the-week-five-photo-storytelling>. Acesso em: 29 jun 2011. 